\title{
Stimulus frequency: Determinant of perception or response?
}

\author{
Warren E. Foote and Leston L. Havens \\ MASSACHUSETTS MENTAL HEALTH CENTER, BOSTON
}

\begin{abstract}
Two stimulus variables, frequency of word usage and word configuration, were investigated tachistoscopically by a method designed to separate their effects on perception and verbal responding. Configurational differences appeared to alter perception. Differences in frequency of usage, however, were associated only with changes in response probability.
\end{abstract}

\section{Problem}

The familiarity of words is generally accepted as a determinant of their recognition ease (Rosenzweig \& Postman, 1958). Support for this observation has come from experiments in which low recognition thresholds have been found for words with a high frequency of usage, and high thresholds noted for low frequency words. Although the evidence attesting to these findings is extensive, it has been obtained largely through the use of a single experimental procedure, viz., unrestricted report of the stimulus. Recently, studies employing modified procedures have questioned the validity of stimulus familiarity as a perceptual determinant (Goldiamond \& Hawkins, 1958; Havens \& Foote, 1963). These studies suggest that stimulus familiarity alters only response probability.

The assumption is that the frequency of word usage variable reflects the availability of word responses to subjects. Subjects are assumed not to have ready access to low frequency word responses and, therefore, reporting these words requires a large number of trials and results in high thresholds. Thus stimulus familiarity is conceived to be a response determinant rather than a perceptual one.

Essential to the problem of ascertaining whether or not a variable affects the perceptual system or the response system is the separation of perception from tre responses used to infer its occurrence (Garner et al., 1956). Since perception is a private affair, knowledge of it is based on inferences made from stimulusresponse contingencies. If subjects respond quickly or more accurately to one class of stimuli than another, some kind of perceptual facilitation may be inferred, but quick and accurate reporting may also be a function of response availability. In the experiment to be reported, we have assumed that if the stimulus materials are kept constant and the manner of obtaining a response is changed, a variable which affects perception should manifest itself despite alterations in responding. On the other hand, if a variable affects the response system and not perception, then its effect should fluctuate concomitantly with differential responding.

\section{Method}

Twelve, five-letter English words were randomly selected from the Thorndike-Lorge compilation. Half of the words had a high frequency of usage, the remaining half a low frequency of usage. The stimuli also differed with respect to configuration. Configuration was defined as the occurrence of either descending letters such as "y," "g" or "p" at the beginning and ending of a word, the occurrence of ascending letters such as "h," "l" or "t" as initial and terminal letters, or the occurrence of flat letters such as "a," "e" or " $r$ " in these positions. The intervening letters were all flat. The words "young," "break," and "ocean" illustrate these three configurational patterns.

All words were typed in lower case by an electric typewriter on white bond paper and presented tachistoscopically under two conditions to 24 subjects. For one half of the subjects a condition of unrestricted verbal report was employed along with the ascending method of limits. Responses of the remaining subjects were restricted to four alternatives presented after each stimulus. These subjects had been informed prior to the experiment that one of the alternatives was the word presented tachistoscopically. The alternatives employed had configurational properties which complemented the stimulus. If the stimulus had a flat configuration, one alternative possessed ascending, the other descending configuration. The fourth alternative served as a foil, having configurational properties selected at random. All the alternatives had the same frequency of usage as the stimulus.

In the restricted condition, all stimuli were presented one after another in random fashion, unlike the usual ascending method of limits procedure. A recognition criterion of three sequentially correct reports was employed for both conditions.

\section{Results}

Recognition time data were logarithmically transformed and subjected to analyses of variance. In both conditions, configuration was observed to be a significant variable. In the condition of unrestricted report, $\mathrm{F}=29.9, \mathrm{df}=2 / 127, \mathrm{p}<.01$; in the condition of restricted report, $\mathrm{F}=18.6, \mathrm{df}=2 / 127, \mathrm{p}<.01$. A hierarchy was noted, words beginning and ending with descending letters being recognized earlier than words with ascending letters and the latter more quickly than flat lettered words (Fig. 1).

Frequency of usage was significant only in the unrestricted verbal report condition where opportunity for response bias and competition are greatest $(F=15.02$, 
$\mathrm{df}=1 / 127, \mathrm{p}<.01$ ). In this condition too, but not in the restricted report condition, there was a significant interaction between frequency and configuration $(\mathrm{F}=$ 12.7, $\mathrm{df}=2 / 127, \mathrm{p}<.01$ ).

\section{Diseussion}

If frequency were a perceptual determinant it should be significant in both conditions. Its significance should not vary with differential responding. These results support previous findings that frequency exerts its affect on threshold by the mechanism of response competition and response competition depends upon configurational fit between stimuli and high frequency responses (Havens \& Foote, 1964). When competition is restricted by response alternatives, a frequency difference fails to appear. Similar results supporting these contentions have been obtained from a study just completed employing alternatives possessing the same configurational properties as the stimulus.

Configuration, on the other hand, is a significant variable in both conditions, suggesting that the overall structure of words as defined by the shape of their composite letters affects perception. This finding serves to emphasize the importance of structural features in word recognition.

The appearance of an interaction between configuration and frequency in the unrestricted report situation is due mainly to low frequency words. We suspect that, while the configurational properties of low frequency words affect thresholds, the results are not uniform since subjects do not have available an equal number of responses for each configurational class. In addition, those responses that were reported often appeared to compete or interfere with correct reports. However, when the inequality is reduced or eliminated by the use of alternatives, in the restricted response condition, configuration is independent of frequency and highly significant.

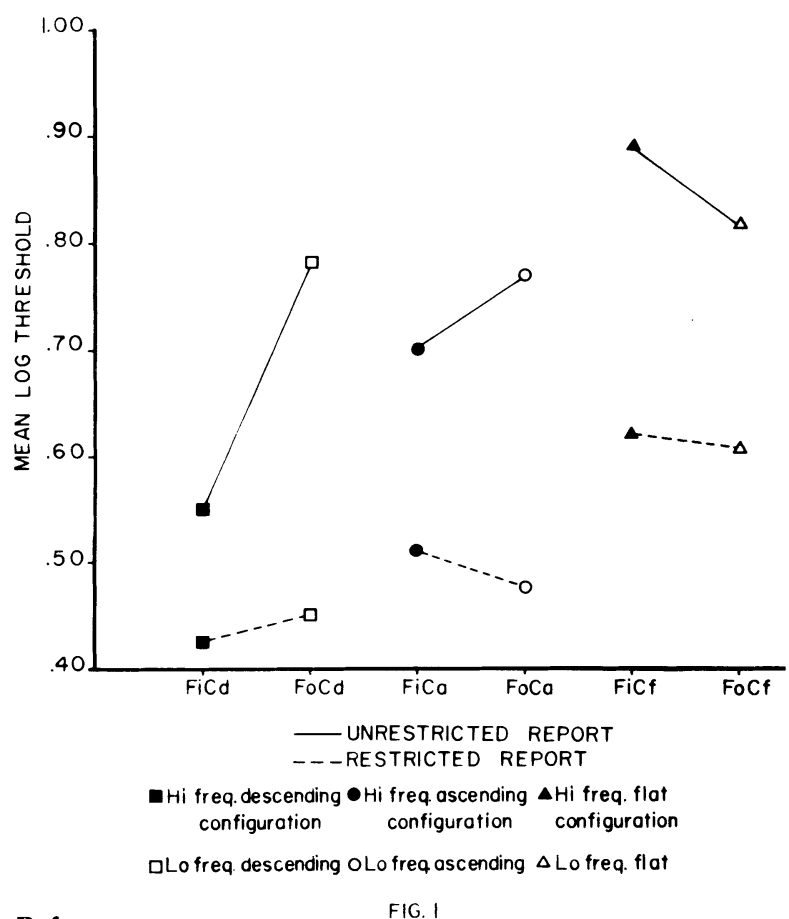

References

FIG. 1

GARNER, W. R., HAKE, H. W., \& ERIKSEN, C. W. Operationism and the concept of perception. Psychol. Rev., 1956, 63, 149-159. GOLDIAMOND, I., \& HAWKINS, W. F. Vexierversuch: the log relationship between word-frequency and recognition obtained in the absence of stimulus words. J. exp. Psychol., 1958, 56, 457-463. HAVENS, L. L., \& FOOTE, W. E. The effect of competition on visual duration threshold and its independence of stimulus frequency. J. exp. Psychol., 1963, 65, 6-11.

HAVENS, L. L., \& FOOTE, W. E. Structural features of competitive responses. Pecept. mot. Skills, 1964, 19, 75-80.

ROSENZWEIG, M. R., \& POSTMAN, L. Frequency of usage in the perception or words. Science, 1958, 127, 263-266.

Note

1. This work was done with the support of National Institutes of Health Grant MH 08112-02. 